\title{
La Bicicleta y el Estado social de derecho
}

\section{Bicycle and social rule of law}

\author{
Francisco J. Bastida Freijedo ${ }^{1}$
}

Fecha de recepción: 27-02-2020 - Fecha de aceptación: 16-06-2020

Hábitat y Sociedad (ISSN 2173-125X), n. . 13, noviembre de 2020, pp. 63-85.

http://dx.doi.org/10.12795/HabitatySociedad.2020.i13.05

\section{Summary}

The aim of this work is analyzing the legal relevance of the bicycle in a social rule of law, as well as the poor and unfortunate legal attention that has been paid to this mode of transport. Its social role has been limited, at least in Spain, to being a toy and a casual instrument of leisure, combined with the political function of extolling patriotic sporting achievements of illustrious cyclists. Until recently, the bicycle suffered a social stigma as a vehicle linked to a status of poverty and insufficient resources to buy a car, of inability to thrive. This social contempt has been reflected in its legal regulation, as will be seen later. It seems however that something is changing presently, mainly at the local government level.

\section{Key words}

Social Rule of Law; Bicycle; Social function; Local government; Personal Mobility vehicles; Environment; Sustainable mobility; Video cam; Criminal law

\section{Resumen}

El objeto de este trabajo es analizar la relevancia jurídica de la bicicleta en el Estado social de derecho y la escasa y desafortunada atención legal que se le ha dado a este medio de desplazamiento. Su función social se ha limitado, al menos en España, a ser juguete e instrumento ocasional de ocio, combinada con su función política de ensalzar patrióticas gestas deportivas de ilustres ciclistas. Hasta hace bien poco la bicicleta ha sufrido como vehículo la estigmatización social, al estar vinculada a un estatus de pobreza, de insuficiencia de recursos para comprar un automóvil, de incapacidad para prosperar. Este desprecio social ha tenido su reflejo en su regulación jurídica, como se verá más adelante. No obstante, parece que algo comienza a cambiar, sobre todo en el ámbito municipal.

\section{Palabras clave}

Estado social de derecho; Bicicleta; Función social; Gobierno municipal; Vehículos de Movilidad Personal; Medioambiente; Movilidad sostenible; Videocámara; Código penal 


\section{Introducción}

El presente trabajo tiene por objeto analizar la relevancia jurídica que debe tener la bicicleta en el Estado social de derecho establecido en nuestra Constitución de 1978. Este deber tiene un sentido ético-político, como desiderátum coherente en un Estado social que busca el bienestar común a toda la sociedad, pero también un deber jurídico que exige que la regulación legal de la movilidad y el medioambiente no solo no contradiga los principios constitucionales del Estado social, sino que los desarrolle y optimice.

El estudio comienza con una teorización sobre la función social de la bicicleta que tuve ya hace años la oportunidad de exponer ante la Comisión de Tráfico y Seguridad Vial del Congreso de los Diputados y que es imprescindible para entender el engarce jurídico de la bicicleta en el Estado social.

A continuación, se realiza un minucioso rastreo de la normativa española sobre la bicicleta, que ofrece un panorama de olvido primero y de exclusión después, ante la abusiva posición de dominio de los vehículos a motor. Se estudia la nula repercusión que ha tenido la proclamación de España como Estado social de derecho en la regulación de la movilidad hasta bien entrado el siglo xxi y cómo en la última década son los ayuntamientos los que, apremiados por la congestión del tráfico de vehículos a motor y sus nocivas consecuencias, impulsan cambios hacia una movilidad sostenible acordes con principios sociales y en los que cobra protagonismo la bicicleta como medio de desplazamiento urbano y no solo como instrumento de ocio. Este giro no ha sido acompañado por una legislación estatal, lo que ha creado no pocos problemas a los municipios, huérfanos de apoyo legal para llevar a cabo las transformaciones hacia un nuevo modelo de ciudad.

En esta visión jurídica de los cambios urbanos de la movilidad, se dedica un epígrafe a la novedosa problemática de la aparición de los llamados Vehículos de Movilidad Personal eléctricos. Una alternativa social a los clásicos vehículos a motor y con una relación de concurrencia colaborativa con la bicicleta, no exenta de fricciones por no ser medios de desplazamiento equiparables.

Por último, se añade un análisis sobre el Estado social y la movilidad de las y los ciclistas como grupo vulnerable y se centra en dos frentes: la protección penal frente a la ominosa irrelevancia del homicidio o de lesiones por imprudencias de conductores de vehículos a motor, y la autodefensa de los ciclistas mediante videograbaciones, lo que puede entrar en conflicto con derechos fundamentales como el de propia imagen y protección de datos personales.

\section{La función social de la bicicleta}

El Estado social de derecho surge frente a una concepción liberal basada en el individualismo posesivo, que considera que el bienestar colectivo es una consecuencia natural de la libertad personal; por tanto, para el liberalismo los poderes públicos no deben interferir en el ejercicio de esa libertad. Históricamente el resultado no fue el esperado y el supuesto orden natural fue, en realidad, un desorden en el que primaban los intereses de los más poderosos, que cada vez son menos, frente a los intereses de la mayoría. Contra esto reaccionó el Estado social, legitimando la intervención pública para impedir que ese desor- 
den hiciera insostenible la vida en sociedad. Esto, en teoría, significa la obligación de los poderes públicos de promover aquellos medios que cumplan entre otros objetivos el establecimiento de un medioambiente saludable y una movilidad sostenible y segura, así como eliminar o desincentivar aquellos otros que dificultan su logro. El problema está en que, por la comodidad y el egoísmo individual, una parte importante de la población, a la vez que exige esas garantías sociales, se resiste a cambiar de hábitos que son los que causan la degradación de la salud medioambiental y la inseguridad en la movilidad; una resistencia que se materializa en la oposición a políticas públicas que obliguen a ese cambio de hábitos. En la medida en que la bicicleta emerge como solución, se concita contra ella una doble animadversión; la clásica de ser considerada un estorbo u obstáculo en la circulación de los vehículos a motor, y la nueva, al ver en ella, y no en la protección de la salud pública, la causa de que se achique el espacio a los vehículos a motor y se rebajen los límites de velocidad.

En el tratamiento jurídico de la bicicleta se suelen confundir dos ideas que, aunque muy relacionadas, apuntan a finalidades diferentes. La protección jurídica de las y los ciclistas y el trato normativo preferente a la bicicleta. La protección jurídica de los ciclistas se debe a que son un colectivo vulnerable frente al peligro objetivo que conlleva la circulación entre vehículos a motor; de ahí la necesidad de medidas que les den prioridad frente a estos vehículos. Sin embargo, la necesidad de un trato normativo preferente a la bicicleta no obedece a la vulnerabilidad del ciclista, sino a la función social que esta cumple, a diferencia de los vehículos a motor. Los medios de transporte colectivo, autobuses, tranvías, no son vehículos vulnerables, pero gozan de un trato preferente por la función social que desarrollan en contraste con los automóviles particulares. Lo mismo sucede con la bicicleta; favorece, además de la salud individual de los ciclistas, la salud colectiva: no contamina el medio ambiente y reduce la siniestralidad directa e indirecta.

Como ya he expresado en otras ocasiones (Bastida, 2014), en términos colectivos, la ampliación de calles restringidas al tráfico, la reducción de los límites de velocidad, los carriles bici, segregados o híbridos, etc. no son medidas a favor del ciclista y en contra de los coches particulares, sino a favor de la ciudad y de su ciudadanía. Si uno de los beneficiarios concretos es el ciclista, lo es por usar un vehículo que favorece la ejecución de esos principios rectores (salud, medioambiente, economía, baja siniestralidad), igual que se favorece al usuario/a de transporte público (carril bus, semáforos inteligentes para el bus, paradas bajo techo e informatizadas, precios públicos), porque coadyuva al cumplimiento de esos principios rectores que mejoran la calidad de vida de la ciudad y de sus ciudadanos y ciudadanas.

Si la bicicleta cumple esa función social en los desplazamientos urbanos es coherente que se arbitren las medidas necesarias para optimizar su uso. Habida cuenta de que el tráfico rodado actual es un terreno hostil para la bicicleta, es necesario pacificarlo, adoptando medidas que reviertan la situación, incluso con regulaciones que podrían calificarse de discriminaciones positivas. Es decir, con normas dirigidas a primar a la bicicleta (vehículo no contaminante y de baja peligrosidad) sobre el coche particular (aunque los usuarios de estos sean más), al objeto de favorecer el acceso al tráfico rodado de quienes desean usarla, pero no se atreven por el temor a un tráfico de alto riesgo, regulado por unas normas diseñadas para la circulación de vehículos a motor. 
Desde la óptica de los intereses colectivos, de ciudad, los conductores y acompañantes de vehículos privados a motor ni siquiera son mayoría frente a la totalidad de la población, que padece los efectos del tráfico de estos vehículos (contaminación del aire y acústica, gasto en infraestructuras y servicios de regulación y mantenimiento, alta siniestralidad, etc.). En términos de libertad, una actividad socialmente nociva debe tener un precio en consonancia con el daño que se genera. En unos casos se paga con la limitación de la libertad (prohibición de circulación en determinadas zonas y horas), en otros con restricciones de espacio, reservando carriles para transporte colectivo o no contaminante, y en otros más pacificando el tráfico con límites más bajos de velocidad máxima permitida o con peajes de acceso al anillo central de la ciudad.

Estas ideas-fuerza que pueden ser consideradas como una concreción del Estado social nunca se han proyectado en la legislación española y solo de manera parcial en las más recientes ordenanzas municipales.

\section{La bicicleta, desplazada por los vehículos a motor. Cien años de soledad}

Antes del advenimiento del automóvil, e incluso muchos años después, la bicicleta era un medio de desplazamiento habitual, junto al caballo y vehículos de tracción animal. Sin embargo, la regulación de la circulación urbana e interurbana es impulsada por la aparición de los vehículos a motor. Un breve repaso histórico de la normativa pone de manifiesto la postergación legal sufrida por la bicicleta en España.

En el siglo XIX se aprueba la Real Orden 31 de julio de 1897 que autoriza a un ingeniero Jefe a dictar normas básicas de circulación ante la incipiente aparición de vehículos a motor. El 16 de septiembre de 1890 se aprueba el Real Decreto que contiene un elemental Reglamento para el servicio de coches automóviles por la carretera. Con posterioridad se aprueba el 16 de junio de 1926 el Reglamento de Circulación de vehículos con motor mecánico y el 17 de julio de 1928 el Reglamento de Circulación Urbana e Interurbana. La atención la monopolizan los vehículos a motor.

Será el 25 de septiembre de 1934 cuando se apruebe el Decreto que establece en España el primer Código de la Circulación y dos días más tarde sus Anexos. La bicicleta solo aparece en un artículo, para indicar el alumbrado que debe llevar. En los Anexos también aparece en un único artículo y es significativo, porque retrata cuál va a ser su situación legal de menosprecio, que se irá reiterando durante todo el siglo Xx. En el Anexo I, dedicado al cuadro de multas, se sanciona:

Por circular bicicletas o vehículos análogos por los pasos o andenes, por el lado izquierdo o centro de las calzadas; por no apartarse a la derecha pegándose a la acera o paseo cuando les avise otro vehículo que vaya detrás; por marchar dos o más de frente, en fila, 10 pesetas. Por ir montadas dos personas en bicicleta construida para una sola, dos pesetas (art. 133).

Este Código de 1934 estuvo vigente más de 50 años, hasta que, 100 años después de aquel primer esbozo de Reglamento del siglo XIX, se aprueba en 1990 una Ley de Tráfico. Por el medio se promulgaron dos leyes, la Ley 47/1959 de 30 de julio, sobre regulación de la competen- 
cia en materia de tráfico en el territorio nacional, que atribuye la función de vigilancia de carreteras y vías públicas al Cuerpo de la Guardia Civil y la Ley 85/1967, de 8 de noviembre, sobre competencia en materia de declaración de aptitud de los conductores de vehículos de tracción mecánica, sin incidencia alguna en la bicicleta.

De la coronación del vehículo a motor como rey del asfalto da fe un cartel publicitario de educación vial auspiciado por la Dirección General de Tráfico (DGT) en los años sesenta, cuya leyenda es "Peatón, respeta al automovilista".

Tras el franquismo, la Constitución de 1978 proclama que España se constituye en un Estado social y democrático de derecho. Como luego se dirá, esta dimensión social tiene un potencial muy grande en el desarrollo de políticas en las que la bicicleta puede jugar un papel relevante; sin embargo, apenas se ha implementado en los cuarenta años de vida constitucional. Obviamente, la Constitución no menciona la bicicleta, aunque sí podría ser relevante su omisión. En su art. 149.1.21 ${ }^{\mathrm{a}}$ dispone que es competencia exclusiva del Estado "el tráfico y circulación de vehículos a motor". ¿Se podría entender que la regulación del tráfico y circulación de bicicletas queda excluida de la competencia exclusiva del Estado? Para las Cortes no. Cuando decidieron sustituir el Reglamento de Circulación de 1934, se entendió que la materia era lo suficientemente importante como para ser regulada por ley y se aprobó La Ley 18/1989, de 25 de julio, de Bases sobre Tráfico, Circulación de Vehiculos a Motor y Seguridad Vial, que dio lugar al Real Decreto Legislativo 339/1990, de 2 de marzo, por el que aprueba el Texto Articulado de dicha ley. Obsérvese que en su título se introduce una coma después de la palabra "Tráfico", que cambia el sentido del art. 149.1.21ª de la Constitución. Ya no es Tráfico (y circulación) de los vehículos a motor, sino que amplía la competencia exclusiva estatal a Tráfico (en general), Circulación de los vehículos a motor, y añade además una nueva competencia, "Seguridad vial". Todo ello en detrimento de las competencias que pudieran alegar sobre la materia las Comunidades Autónomas.

La Ley de Tráfico, en su redacción inicial de 1990, ignora prácticamente a las y los ciclistas y a las bicicletas. Solo se refiere a la prohibición de estacionar en los pasos para ciclistas (art. 39.1 b), sin aclarar en qué consisten, y a una escueta definición de bicicleta como "ciclo de dos ruedas" (Anexo. 6). Lo mismo sucede en su desarrollo reglamentario hecho por el Real Decreto 13/1992, que aprueba el nuevo Reglamento General de Circulación y que deroga parcialmente el de 1934 (solo derogado de manera definitiva por el Real Decreto 818/2009, que aprueba el Reglamento General de Conductores).

\section{La incipiente visibilidad legal de la bicicleta}

El ostracismo legal al que se sometió a la bicicleta en España llega prácticamente hasta el último año del siglo $\mathrm{xx}$, cuando se aprueba la Ley 43/1999, de 25 de noviembre, sobre adaptación de las normas de circulación a la práctica del ciclismo. Con este significativo título la legislación reconoce que "la bicicleta es un eficaz medio de transporte que representa una alternativa cotidiana viable para muchas personas", y también el problema que supone que "el uso de la bicicleta se ve en la actualidad limitado y estrictamente condicionado por el gran medio de transporte de nuestros tiempos: el automóvil de motor". Se admite el riesgo y las dificultades que entraña el uso de la bicicleta frente a los vehículos a motor: 
La masiva y generalizada utilización de estos vehículos, la predominante adecuación a ellos, tanto de las infraestructuras viarias como de la normativa circulatoria, restringen, desde un punto de vista meramente físico como desde una perspectiva jurídico-formal, el ámbito de utilización sin riesgo y las posibilidades de disfrute de la bicicleta. El logro de una situación equilibrada y una óptima utilización de los distintos medios de transporte imponen la búsqueda de soluciones de combinación entre aquéllos, con fórmulas que se refieren tanto a la ordenación del espacio físico, principalmente, la construcción de pistas ciclables, como a la reglamentación viaria favorecedora del uso de la bicicleta.

Pese a las apariencias, la reforma no supuso ninguna revolución en la movilidad; más bien lo contrario. La introducción de puntuales y muy escasos favores a las y los ciclistas se combinó con importantes obligaciones y prohibiciones. Por ejemplo, se permite a las bicicletas circular en paralelo, aunque en las condiciones que disponga el futuro Reglamento de la Circulación. Se mantiene la regla general de prioridad de paso de los vehículos a motor sobre peatones y ciclistas, pero ahora se prevén algunas mínimas excepciones, que en el caso de las bicicletas son: la existencia de carriles bici o de paso para ciclistas, o "cuando para entrar en otra vía un vehículo gire a la derecha o a la izquierda, en los supuestos permitidos, existiendo un ciclista en sus proximidades, bien en la propia calzada, bien en el carril-bici o en el arcén derecho".

En cuanto a las obligaciones, se impone el casco ciclista en vías interurbanas de acuerdo con lo que disponga el reglamento. También la exigencia de que las bicicletas tengan elementos reflectantes homologados y de que los ciclistas, cuando sea obligatorio el uso de alumbrado, deberán llevar una prenda reflectante por vías interurbanas. Igualmente, se extiende a los ciclistas el control del consumo de alcohol y drogas. Por lo que respecta a las prohibiciones, las bicicletas, que ya no podían circular por las autopistas, tampoco podrán hacerlo ahora por las autovías, e incluso se autoriza al reglamento para prever limitaciones temporales o permanentes en las demás vías cuando así lo exija la seguridad o la fluidez de la circulación.

En suma, se atiende a la seguridad del tráfico y a la fluidez de la circulación de los vehículos motorizados, pero no a la posibilidad de un uso efectivo de la bicicleta ni a una movilidad sostenible.

La Ley 19/2001, de 19 de diciembre reforma de nuevo el texto articulado de la Ley aprobado en 1990. Su principal objeto no era mejorar las condiciones de movilidad del ciclista; de hecho, en la exposición de motivos no hay ninguna mención al respecto, que se centra en la modificación de infracciones y sanciones. Sin embargo, introduce cambios relevantes para la circulación en bicicleta. Por ejemplo, se corrige el criterio establecido en 1999 y se abre la posibilidad de que las bicicletas circulen por las autovías, siempre que lo hagan por el arcén. No obstante, en vías interurbanas debe circular también por el arcén de su derecha, si fuera practicable y si no, por la parte imprescindible de la calzada. Se permite en determinadas condiciones, singularmente en descensos, que en vías normales el ciclista sobrepase la velocidad de vehículos lentos y ocupe la derecha de la calzada, abandonando el arcén. Se permite a los ciclistas circular en grupo, extremando la atención para evitar el alcance entre ellos. Transitando en grupo en zonas interurbanas y a los efectos de prioridad de paso, los ciclistas son considerados una única unidad móvil. En cuanto al adelantamiento de ciclistas se permite invadir la parte izquierda del carril, aun con raya con- 
tinua, siempre cerciorándose de que no exista peligro. Igualmente, no se puede adelantar a otro vehículo entorpeciendo o poniendo en peligro a ciclistas que circulen en sentido contrario. También se protege al conductor de bicicleta, prohibiendo la apertura de puertas de un vehículo sin antes comprobar la ausencia de ciclistas. En el Anexo de la Ley se introducen nuevos conceptos y señales como los referidos a Vía ciclista, Carril-bici, Acera-bici, Pista-bici y Senda ciclable.

En suma, se trata de medidas concretas que se aprueban ante insistentes reivindicaciones de colectivos ciclistas, sobre todo de carretera, pero en nada cambia el sentido general de la norma, que sigue pensada en y para los vehículos a motor. Podría decirse que la bicicleta es considerada una intrusa desde el punto de vista social, repudiada por peatones y por automovilistas, y también desde el punto legal. Su regulación es escasa y aparece inserta de mala manera en la propia de los vehículos a motor. Esta anomalía se advierte, por ejemplo, en el capítulo de sanciones, que no tiene en cuenta la menor peligrosidad de las infracciones ciclistas respecto de la de los vehículos a motor. También en la indiferenciación con que se aplica a las bicicletas una normativa pensada para los automóviles.

Estas dos reformas legislativas dieron lugar a un nuevo Reglamento General de Circulación que las desarrolla, aprobado por el Real Decreto 1428/2003, y que deroga el de 1992. Este Reglamento de 2003, todavía vigente, no aclara las dudas que la legislación suscita. Más bien intenta resolverlas por una vía interpretativa poco favorecedora de la bicicleta, como es el caso, por ejemplo, de las sillas y de los remolques para bicicletas o el de las marchas ciclistas.

Años más tarde se aprueba la Ley 18/2009, que reforma una vez más la Ley de Tráfico, Circulación de Vehículos a motor y Seguridad vial de 1990. Se refiere a materia sancionadora y tiene cierto interés porque por primera vez distingue la calificación de algunas infracciones según el tipo de vehículo. Lo lamentable es que se trata de mínimas excepciones dentro de una general indiferenciación. Así, en el caso de las bicicletas se consideran infracción leve solo dos supuestos: circular sin hacer uso del alumbrado reglamentario y no hacer uso el ciclista de los elementos y prendas reflectantes cuando sea obligado. También establece que adelantar poniendo en peligro o entorpeciendo a ciclistas está sancionado con la pérdida de cuatro puntos del permiso de conducir. Además, corrige una torpe aplicación de la Ley 17/2005, reguladora del permiso y la licencia de conducción por puntos, que podía ocasionar a un ciclista infractor de una norma de tráfico la pérdida de puntos de su permiso de conducir vehículos a motor. La Ley de 2009 aclaró que "la pérdida de puntos únicamente se producirá cuando el hecho del que se deriva la detracción de puntos se produce con ocasión de la conducción de un vehículo para el que se exija autorización administrativa para conducir"; por tanto, no es de aplicación a ciclistas.

En 2013 se inician los trabajos para reformar el Reglamento General de Circulación de 2003 y uno de sus principales objetivos era adecuar la regulación del tráfico a la cada vez mayor movilidad ciclista, sobre todo en las zonas urbanas. En la exposición de motivos del borrador del nuevo Real Decreto se lee:

En los últimos años, una de las grandes transformaciones que ha vivido el país ha sido la de las ciudades y pueblos en los que vivimos, y, por lo que respecta a la movilidad urbana, hay un aspecto esencial que se constata, y es que se ha dado un importante protagonismo a los peatones y a las bici- 
cletas, lo cual ha configurado un nuevo concepto de ciudad más sostenible y más cómoda. La pérdida de protagonismo del vehículo a motor y, por el contrario, el auge de otros medios para desplazarse, es un cambio cultural importante que es necesario también trasladar a la norma, con objeto de dotar a los usuarios de las vías de la necesaria seguridad jurídica.

La nueva norma pretendía crear un marco básico que sirviese para dar cobertura a una regulación municipal que ya se estaba produciendo en algunas ciudades, preocupadas por la movilidad sostenible y con iniciativas en favor de la peatonalización y del uso de la bicicleta, y de la restricción del uso de vehículos a motor. Para amparar estas políticas, el borrador preveía medidas para la pacificación del tráfico urbano, la potenciación de la bicicleta y la reducción de la siniestralidad en zona urbana. Una de las innovaciones más importantes era la Ciudad 30, limitando la velocidad máxima en las calles de un solo carril por sentido a $30 \mathrm{Km} / \mathrm{h}$ y, de haber varios, al menos el de la derecha tendría igual limitación. También introducía el concepto de "vía de plataforma única" que, en realidad da nombre a algo ya existente en casi todas las ciudades como son las calles peatonales de tráfico restringido.

Otra de las novedades relevantes era la introducción de un título específico sobre la bicicleta como medio de transporte urbano que supondría un avance significativo. Por ejemplo, permitía en determinados casos poder circular los menores en bicicleta por la acera, establecía la posibilidad de adelantar las bicicletas a los vehículos parados hasta llegar al semáforo, prioridad ciclista en las glorietas, posibilidad de circular las bicicletas en contrasentido en calles de dirección única y de transportar personas y mercancías en remolque de bicicleta. Por el contrario, contenía medidas nocivas para la promoción del uso de la bicicleta: obligatoriedad del casco ciclista también en ciudad, elevación de la edad (a 18 años) para circular en bicicleta por las autovías (siempre por su arcén). Además, se preveía un "cierre de la vía por uso excepcional" que podría ser inconstitucional en la medida en que interfiriese en el ejercicio del derecho fundamental de manifestación. Como remate, reformaba a peor la regulación de las marchas ciclistas, dificultando gravemente su realización.

La Mesa Española de la Bicicleta, constituida por aquel entonces por la Real Federación Española de Ciclismo, la Asociación de Ciclistas Profesionales, ConBici, Ambe y CicloJuristas, presentó objeciones de constitucionalidad y de legalidad, así como enmiendas a la pretendida reforma reglamentaria, lo que seguramente influyó en su aplazamiento a la espera de una ley que diese suficiente cobertura legal.

\section{El estancamiento legal}

El Gobierno presentó al poco tiempo un proyecto de Ley que consistió en un parche más a la Ley de Tráfico y que las Cortes aprobaron con celeridad, la Ley 6/2014, de 7 de abril por la que se modifica el texto articulado de la Ley sobre Tráfico, Circulación de Vehiculos a Motor y Seguridad Vial, aprobado por el Real Decreto Legislativo 339/1990, de 2 de marzo. Una Ley que incluye lo negativo que había en el proyecto de Reglamento, singularmente la obligatoriedad del casco ciclista también en ciudad, aunque se rebajó la edad (a menores de 16 años), y no incorpora lo que de bueno para el uso de la bicicleta había en él. Tampoco se atendió a una ya clásica reivindicación de cambio en el régimen sancionador en 
relación con la actividad ciclista, para que se introdujesen criterios de proporcionalidad tanto en las infracciones como en las sanciones, eliminándose la injusta equiparación del riesgo social de las bicicletas con el generado por los vehículos a motor.

Con la Ley ya aprobada, se presentó de nuevo el proyecto de Reglamento con ligeras variaciones. Tras un periodo de alegaciones, en el que se pudo comprobar la animadversión de determinados colectivos e instituciones hacia la bicicleta, se produjo el dictamen del Consejo de Estado 885/2014, que no ocultó en ningún momento sus prejuicios hacia la reforma, algo difícilmente comprensible en un órgano al que hay que exigirle rigor jurídico y no posicionamientos en contra de un tipo de movilidad, máxime cuando no se corresponden con el principio de Estado social que proclama la Constitución.

Para el Consejo de Estado la reforma que promueve el Gobierno pretende un cambio en el modelo de movilidad que no está en la Ley y que consiste en el abandono de los vehículos a motor y el fomento del uso de las bicicletas.

Este sistema, a falta de las infraestructuras necesarias - dice el Consejo- exige el sacrificio de los automóviles y sus conductores, que habrán de reducir sustancialmente la velocidad (a $30 \mathrm{~km} / \mathrm{h}$ ) y el sacrificio de los peatones, que habrán de acomodarse a la presencia de las bicicletas en las aceras y zonas peatonales. Las ciudades se verán así ralentizadas o, como señala la memoria, pacificadas.

En ningún precepto constitucional o legal se afirma como sostiene el Consejo de Estado que el cambio del modelo de movilidad urbana tenga que hacerse por ley. Es obvio que se trata de una competencia municipal. Tampoco es cierto que el proyecto presente como demanda ciudadana "el abandono de los vehículos a motor y su sustitución por las bicicletas". La pretensión es mucho menos ambiciosa y en ningún caso se planea en términos de sacrificio, sino de convivencia.

Según el Consejo se hace pasar como demanda social general lo que es solo una demanda de los ciclistas, "sin que esta ampliación se sustente en dato alguno". Parece que las demandas municipales, que constan en la memoria normativa del proyecto, no tienen relevancia. Pocas veces el Consejo de Estado ha estado tan desafortunado en sus juicios, no solo por su falta de fundamento jurídico, sino también y sobre todo por su falta de objetividad y por sus lamentables prejuicios en contra de la bicicleta y de la movilidad sostenible.

En lo que sí tiene razón es que el proyecto de Reglamento invade competencias municipales, tal como había advertido en su informe la Mesa española de la Bicicleta, lo cual no casa bien con su argumento de que un cambio en el paradigma de la movilidad urbana debe regularse por ley.

La Ley 6/2014 no solo fue una oportunidad perdida para integrar en su contenido las medidas favorables hacia una movilidad sostenible apuntadas en el proyecto de reforma del Reglamento General de Circulación. Lo fue también porque, lejos de sentar las bases de una ley de nueva planta de movilidad segura y sostenible, autorizó al Gobierno para aprobar una mera refundición de textos legales sobre tráfico y seguridad vial. Fruto de ello fue el Real Decreto Legislativo 6/2015, de 30 de octubre, por el que se aprueba el texto refundido de la Ley sobre Tráfico, Circulación de Vehículos a Motor y Seguridad Vial. Veinticinco años después de la aprobación de esta Ley, la movilidad urbana ha cambiado mucho, pero 
las Cortes Generales siguen con el mismo paradigma de movilidad, basado en la supremacía del vehículo a motor, con un consentido abuso de su posición de dominio.

\section{Sostenibilidad medioambiental, movilidad y Estado social de derecho}

La Constitución proclama que España es un Estado social (art. 1.1), lo cual significa que los poderes públicos deben actuar, entre otros fines, para que la libertad y la igualdad individual y colectiva sean reales y efectivas (art. 9.2), para establecer políticas que protejan la salud pública y fomenten la educación física y el deporte (art. 43) y para proteger el derecho de todos a disfrutar de un medio ambiente adecuado para el desarrollo de la persona, (art. 54). Además, toda la riqueza del país en sus distintas formas y sea cual fuere su titularidad está subordinada al interés general (art. 128). Todo ello exige en su conjunto políticas integrales, sin que las especialidades temáticas puedan desligarse de los principios y fines generales que guían el Estado social.

En contraste con lo que debiera de ser, llama la atención la falta de coherencia política al no regular de manera global un fenómeno complejo como es la sostenibilidad medioambiental, una de cuyas piezas maestras es la movilidad. Mientras en materia de Tráfico las medidas van dirigidas a organizar la circulación de los vehículos a motor y garantizar la seguridad vial y no una movilidad que además de segura sea sostenible, en materia energética se busca un modelo sostenible, que impulse la reducción de emisiones y los proyectos de transportes más eficientes. Así, cuatro años antes de que se publique el mencionado Real Decreto Legislativo 6/2015, que aprueba el texto refundido de la Ley sobre Tráfico, se promulga la Ley 2/2011, de 4 de marzo, de Economía Sostenible, que tiene entre sus objetivos de política de movilidad "fomentar los medios de transporte de menor coste social, económico, ambiental y energético, tanto para personas como para mercancías, así como el uso de los trasportes público y colectivo y otros modos no motorizados" y "el desarrollo de modos alternativos al vehículo privado" (art. 100.4 y 5). La contradicción es manifiesta e incomprensible, porque no se pueden tener tales objetivos y a la vez perpetuar una legislación que sigue potenciando los vehículos a motor y que ve con recelo a las bicicletas y a los vehículos de movilidad personal (VMP).

La timidez a la hora de afrontar una política seria en esta materia se ve en los propios planes de movilidad. La citada Ley 2/2011 establece como una de sus piezas maestras los Planes de Movilidad Sostenible, que:

Son un conjunto de actuaciones que tienen como objetivo la implantación de formas de desplazamiento más sostenibles en el ámbito geográfico que corresponda, priorizando la reducción del transporte individual en beneficio de los sistemas colectivos y de otros modos no motorizados de transporte y desarrollando aquellos que hagan compatibles crecimiento económico, cohesión social, seguridad vial y defensa del medio ambiente, garantizando, de esta forma, una mejor calidad de vida para la ciudadanía. Estos planes deberán dar cabida a soluciones e iniciativas novedosas, que reduzcan eficazmente el impacto medioambiental de la movilidad, al menor coste posible (art. 101.1). 
Pues bien, los sucesivos planes para reducir los vehículos a motor de gasolina o diésel se centran exclusivamente en los vehículos eléctricos, ignorando la bicicleta y solo previendo algunos años mínimas ayudas a la compra de bicicletas eléctricas (e-bikes). Entre 2013 y 2016 los planes PRIMA AIRE contemplaban junto a las grandes subvenciones a los coches eléctricos, una pequeña ayuda para la adquisición de estas bicicletas, limitada en su cantidad global y que normalmente beneficiaba más al vendedor que al comprador. En el Plan MOVEA de 2017 se olvidaron en su ejecución de estas subvenciones a las e-bikes y en el plan MOVALT, de 2018, destinado a incentivar la compra de vehículos movidos por energías alternativas y la instalación de punto de recarga eléctrica, ni se mencionan. En este campo de las subvenciones una pequeña luz se abre con el programa MOVES, aprobado por el Real Decreto $72 / 2019$, que regula el programa de incentivos a la movilidad eficiente y sostenible. Aunque el grueso de las ayudas se concentra en la adquisición de coches eléctricos y estaciones de recarga, se contemplan también como actuaciones subvencionables la implantación de sistemas de préstamos de bicicletas eléctricas y el establecimiento de medidas contenidas en planes de transporte al trabajo en empresas (inversión en aparcamiento de bicicletas, dotación de vestuarios, etc). Nada, sin embargo, para las bicicletas convencionales, ni siquiera en beneficios fiscales como sí sucede en la adquisición de coches eléctricos.

Ante la pasividad del Gobierno, la Mesa Española de la Bicicleta diseñó en 2014 unas directrices para un Plan Nacional de la Bicicleta, que ha servido de base para el Plan Estratégico Estatal de la Bicicleta, acogido por el Gobierno y en fase de elaboración, en cuyos trabajos participan tanto colectivos privados como organismos públicos. El Plan se denomina actualmente Estrategia Estatal por la Bicicleta y el cambio de nombre no parece muy afortunado, porque la referencia expresa a que se trata de un Plan enmarcaría de manera positiva la Estrategia en uno de los instrumentos de la Ley de Economía Sostenible, los planes de movilidad.

La Estrategia Estatal por la Bicicleta se fija un plazo 2020-2025, y fija cinco prioridades: conseguir un cambio modal a la bicicleta, promover la vida saludable de las personas, fomentar y proteger el ocio y el deporte en bicicleta, aprovechar el potencial del turismo en bicicleta y coordinar la acción del Estado. La elaboración de la Estrategia gira en torno a seis ejes: promoción y fomento de la bicicleta, seguridad y regulación de la bicicleta, impulso de la movilidad ciclista, desarrollo del turismo en bicicleta, iniciativa empresarial sobre la bicicleta y acción institucional por la bicicleta.

\section{El cambio del modelo de movilidad urbana y las competencias municipales}

Frente a la pasividad o extrema lentitud del Estado en esta materia, cada vez más ayuntamientos, grandes y pequeños, se deciden a actuar por su cuenta para organizar una movilidad acorde con una nueva filosofía social y medioambiental que potencia los desplazamientos a pie y en vehículos no contaminantes, recalifica para ello el viario urbano y limita y desincentiva de diversas formas el uso del vehículo a motor privado. La primera cuestión que se suscita es si los ayuntamientos tienen competencia para abordar estos cambios, algo que pone en duda sin fundamento el Consejo de Estado. 
La Constitución reconoce a los municipios autonomía (art. 140) y la Ley 7/1985, de 2 de abril, Reguladora de las Bases de Régimen Local dispone con carácter general que las entidades locales gestionan con autonomía sus intereses propios (art. 1). Además, las Leyes básicas del Estado determinan las competencias que ellas mismas atribuyan a los entes locales o que, en todo caso, deban corresponderles en las materias que regulen (art. 2.2). Las competencias municipales son propias o por delegación (art. 7.1); las competencias propias solo pueden ser determinadas por ley (art. 7.2) y las delegadas, conforme a los términos de la delegación (art. 7.3). Sin embargo, la Ley misma 7/1985 admite la posibilidad de que gestionen otras competencias distintas, siempre que no se ponga en riesgo la sostenibilidad financiera de la Hacienda municipal y que se ejerzan en los términos previstos en la legislación estatal y autonómica (art. 7.4). En este marco estatal y autonómico la citada Ley reconoce en su art. 25.2 como competencias municipales propias, entre otras, urbanismo, medio ambiente, infraestructura viaria, policía local, tráfico, estacionamiento de vehículos y movilidad, transporte colectivo urbano y protección de la salubridad pública.

$\mathrm{Al}$ estar las competencias municipales, propias o delegadas, supeditadas al marco legislativo estatal y autonómico, surge la duda de cuál es el ámbito de esta reserva de ley y su posible conflicto con la garantía constitucional de la autonomía local. La sentencia del Tribunal Constitucional (STC) 42/2018 basa el criterio de delimitación en tres ideas: libertad de configuración del legislador en la distribución de funciones Estado-entes locales, pero deber de graduar su intervención en función de intereses locales y deber de asegurar la capacidad decisoria municipal en intereses locales. Para controlar la constitucionalidad de estas leyes respecto de la autonomía local el Tribunal Constitucional las somete a un test que deben cumplir: justificación de existencia de intereses supralocales, ponderación de intereses locales afectados y garantía a los ayuntamientos de un nivel de intervención correlativo a sus intereses locales.

Todo ello significa que hay una reserva flexible de ley. Que lo que antaño se entendía como una vinculación positiva de las ordenanzas a la ley (ordenanzas solo secundum legem, previa existencia de ley) hoy se interpreta como una vinculación negativa (ordenanzas praeter legem, posibilidad de ordenanzas en ausencia o inactividad de la ley), criterio avalado por la Carta Europea de la Autonomía local $(1985,1989)$ y por SSTC233/1999; 132/2001 y Dictamen 1749/1994 del Consejo de Estado. La norma municipal no es la ejecución de una voluntad ajena, sino desarrollo de un poder propio. Entre Ley y ordenanza municipal hay una relación interordinamental, no una relación simplemente internormativa, de lo cual se deriva la existencia de potestades municipales implícitas, reforzadas por el carácter democrático de los ayuntamientos.

En apariencia esta doctrina amplía de manera considerable la autonomía municipal, al no estar supeditado el municipio a ser mero ejecutor de la ley. El problema surge cuando la ley a la que está vinculado es muy expansiva y excesivamente detallista, porque cuanto más lo sea, menos margen de vinculación negativa le queda al municipio, y eso precisamente es lo que sucede con la Ley de Tráfico, Circulación de Vehículos a motor y Seguridad vial que afectan a cualquier tipo de terreno apto para circular, sea urbano o interurbano y a cualquier persona usuaria de la vía, sea conductora o peatón, circule por la calzada o por la acera. Para el Tribunal Supremo esta expansividad de la Ley de 
Tráfico no es inconstitucional. La Ley puede regular cuestiones locales y solo lesionará la autonomía local si causa una grave perturbación de la gestión municipal (STS 10 de abril de 2014 sobre la ordenanza de movilidad de Zaragoza).

No obstante esa expansividad, la Ley de Tráfico atribuye en su art. 7 a los municipios, entre otras competencias:

a) La regulación, ordenación, gestión, vigilancia y disciplina, por medio de agentes propios, del tráfico en las vías urbanas de su titularidad, así como la denuncia de las infracciones que se cometan en dichas vías y la sanción de las mismas cuando no esté expresamente atribuida a otra Administración. b) La regulación mediante ordenanza municipal de circulación, de los usos de las vías urbanas, haciendo compatible la equitativa distribución de los aparcamientos entre todos los usuarios con la necesaria fluidez del tráfico rodado y con el uso peatonal de las calles, así como el establecimiento de medidas de estacionamiento limitado, con el fin de garantizar la rotación de los aparcamientos, prestando especial atención a las necesidades de las personas con discapacidad que tienen reducida su movilidad y que utilizan vehículos, todo ello con el fin de favorecer su integración social.

Además, tienen competencia para "g) la restricción de la circulación a determinados vehículos en vías urbanas por motivos medioambientales".

Por tanto, los municipios tienen mimbres legales suficientes para establecer su propio modelo de movilidad y, como ya se dijo, carece de fundamento la afirmación del Consejo de Estado de que el modelo de ciudad tenga que hacerse por ley. Además, el modelo de movilidad no solo se hace mediante normas de tráfico y circulación. Existe un conjunto de planes y ordenanzas que confluyen en su diseño y realización. El plan de ordenación urbana condiciona el modelo de ciudad, no solo desde el punto de vista de la edificación, zonas verdes y espacios peatonales, sino también de la configuración de la red viaria municipal. La ordenanza propiamente de movilidad es la que de manera más inmediata organiza el uso concreto de las vías, definiendo los tipos de viales y los modos de uso. Así, el modelo de movilidad cambia simplemente alterando la calificación de las vías e incluso de sus carriles. Una calle abierta al tráfico en general puede pasar a ser zona peatonal; un carril destinado a aparcamiento puede transformarse en carril reservado al transporte público o a bicicletas y VMP; se puede rebajar la velocidad máxima en toda la red viaria y convertir la ciudad en una Ciudad 30; es posible cerrar al tráfico de determinados vehículos zonas congestionadas, etc. Por otra parte, la rigidez de las definiciones que contiene la Ley de Tráfico se puede evitar cambiando la calificación de la vía; por ejemplo, una "zona peatonal" es según la Ley una zona de exclusivo uso para los peatones, pero basta con tipificar esa zona como calle de tráfico restringido a residentes, servicios público y bicicletas para que, siendo de uso preferentemente peatonal, quede abierta a las bicicletas y a vehículos concretos. También se puede poner debajo de la señal de prohibición las excepciones que crea convenientes el ayuntamiento, permitiendo el paso de bicicletas y de VMP.

Junto a la ordenanza de movilidad, existen otras que contribuyen igualmente a perfilar el modelo de movilidad y su sostenibilidad. Por ejemplo, las ordenanzas sobre aparcamientos, transporte público y sistemas de alquiler de vehículo compartido, medio ambiente y ruido, sin 
olvidar las ordenanzas fiscales que establecen precios y tasas, fijan impuestos a los vehículos a motor y pueden crear subvenciones a la movilidad sostenible.

Sería deseable que se sustituyese la actual Ley, centrada en el tráfico, circulación de vehículos a motor y seguridad vial, por otra más global y actual, que regulase las bases de una movilidad sostenible, dejando su concreción urbana a cada municipio. No obstante, como queda dicho, los ayuntamientos tienen instrumentos legales para hacer frente a los nuevos retos de la movilidad del siglo xxi. Prueba de ello son las nuevas ordenanzas de movilidad de cada vez más ayuntamientos, favoreciendo el desplazamiento a pie y en bicicleta, regulando nuevas modalidades de transporte no contaminante y estableciendo medidas que directa e indirectamente desincentivan el uso de vehículos a motor no eléctrico.

\section{Movilidad sostenible y la aparición de los Vehículos de Movilidad Personal}

Los VMP han sido, en general, bien recibidos como una alternativa a los vehículos tradicionales de cuatro ruedas porque son ligeros y no contaminan. Sin embargo, su propia denominación oculta la realidad de que son vehículos con motor eléctrico y no pueden emparentarse sin más con las bicicletas. Estas también son vehículos de movilidad personal, pero se ayudan de la fuerza muscular para circular, no de un motor eléctrico. Por tanto, la denominación más exacta de estos nuevos ingenios sería VEMP (E de eléctrico). Existen también bicicletas eléctricas de asistencia al pedaleo (epac), pero para estar equiparadas a las bicicletas normales y estar exentas de homologación, no pueden tener acelerador, no puede sobrepasar su motor los $250 \mathrm{~W}$ y se corta progresivamente el suministro de potencia cuando alcanza una velocidad de $25 \mathrm{~km} / \mathrm{h}$ (Art. 2.2.h del Reglamento UE 168/2013). Si no cumplen estas condiciones se consideran ciclos de motor.

Desde el punto de vista global de la movilidad es importante diferenciar entre los modos activos de desplazamiento y los modos pasivos. Los modos activos (a pie o en bicicleta) son doblemente saludables, porque no solo favorecen la salud individual de quien los practica, sino también la salud colectiva, al no contaminar el ambiente con gases nocivos y ruido. Los VMP son modos pasivos, por lo que, aunque no contaminan directamente el ambiente, no propician el ejercicio físico, lo que les priva de esa función no solo individual, de mantenimiento de la salud del conductor o conductora, sino también social, porque reduce el gasto sanitario. A la hora de fomentar la movilidad sostenible y de regular las prioridades y preferencias en la circulación, los poderes públicos deberían tener en cuenta esta diferencia fundamental entre modos activos y pasivos de desplazamiento.

La aparición de los VMP ha planteado serios problemas de legalidad, por la indefinición o simple vacío legal de un fenómeno que se ha extendido en múltiples direcciones. Bajo estas siglas se esconde una variada tipología de vehículos que todos tienen en común el ser movidos por motor eléctrico, pero con diferentes propiedades y usos: desde los que no son más que juguetes a los que por velocidad y potencia son equiparables a ciclomotores; desde los de uso privado exclusivo, a los de uso en alquiler compartido, uso turístico, uso como transporte de mercancías, etc. Ante la pasividad del legislador o porque se consi- 
deró que la autonomía local y los poderes implícitos municipales autorizaban a ello, algunos ayuntamientos pioneros, como el de Barcelona, aprobaron normativas específicas y más tarde otros siguieron su ejemplo o fueron integrando en la ordenanza de movilidad normas particulares sobre estos ingenios mecánicos, creando categorías de VMP y estableciendo por cuáles vías pueden circular. Una de las más recientes es la ordenanza de movilidad de Sevilla.

El problema jurídico de los VMP es que se trata de unos vehículos no contemplados en el Reglamento General de Vehículos aprobado por Real Decreto 2822/1998, actualmente en fase de reforma para incluir su regulación y que, como se acaba de decir, bajo la denominación de VMP se cobijan muy distintos tipos de vehículos eléctricos. Para mayor confusión, se ha tomado como referencia para clasificarlos el Reglamento (UE) 168/2013 del Parlamento Europeo y del Consejo, de 15 de enero de 2013, relativo a la homologación de los vehículos de dos o tres ruedas y los cuatriciclos. Se trata de una norma que, como su título expresa, se refiere a homologación de vehículos y en función de ella, establece en su Anexo I una clasificación de los mismos. Pero la normativa española ha tomado esta clasificación como referencia para otras cuestiones diferentes, como son el permiso para conducirlos, la obligatoriedad del casco, o los tipos de vías por las que pueden circular.

El Reglamento UE deja fuera de su ámbito de homologación, entre otros vehículos: los de una rueda (art. 2.1); aquellos cuya velocidad máxima no supere los $6 \mathrm{~km} / \mathrm{h}$ (2.2.a); los destinados exclusivamente a ser utilizados por personas con discapacidad física (art. 2.2.b); las bicicletas con asistencia al pedaleo, equipadas con un motor eléctrico auxiliar, de potencia nominal continua máxima inferior o igual a 250 $\mathrm{W}$, cuya potencia disminuya progresivamente y que finalmente se interrumpa antes de que la velocidad del vehículo alcance los $25 \mathrm{~km} / \mathrm{h}$ o si el ciclista deja de pedalear (art. 2.2.h); los vehículos autoequilibrados (art. 2.2.i); los que carecen de una plaza de asiento como mínimo (art. 2.2.j); los equipados con cualquier plaza de asiento para el conductor en los que el punto $\mathrm{R}$ se sitúe a una altura inferior o igual a $540 \mathrm{~mm}$ en el caso de las categorías L1e, L3e y L4e, o inferior o igual a $400 \mathrm{~mm}$ en el caso de las categorías L2e, L5e, L6e y L7e. Esta norma europea no está exenta de contradicciones; por ejemplo, excluye a los vehículos autoequilibrados y a los que carecen de asiento o tienen un asiento bajo, sin consideración a la velocidad que pueden desarrollar y a la potencia que pueden tener. Pero, al margen de ello, está claro que a efectos de circulación y seguridad vial la exclusión de homologación no implica una equiparación de los vehículos excluidos y de sus conductores, lo que significa que pueden ser sometidos a calificaciones, condiciones y requisitos distintos. Un patinete eléctrico puede que esté exento de homologación, pero a efectos de circulación podría ser clasificado como un ciclomotor.

Ante el vacío legal y la iniciativa asumida por algunos ayuntamientos para regular un fenómeno tan novedoso como falto de control, la Dirección General de Tráfico dictó tres Instrucciones al respecto, una en 2016 y dos en 2019. La Instrucción de 2016 16/V-124, sobre Vehículos de Movilidad Personal, comete el grave error de afirmar que estos vehículos no son vehículos de motor, cuando lo cierto es que están dotados de al menos un motor eléctrico, y no diferencia tipos de VMP según la potencia. A partir de ahí extrae conclusiones que inducen a confusión: los VMP podrían circular por la acera, salvo que se les equipare a las bicicletas, no necesitan seguro de responsabilidad 
civil y no precisan un permiso de circulación ni de conducción. Solo prevé la necesidad de autorización municipal para los VMP destinados a actividad comercial.

La Instrucción 19/V-134, sobre matriculación de vehículos L1e-A, deduce de la necesaria homologación de estos vehículos según el Reglamento UE 168/2013 la obligación de su matriculación, lo cual no es correcto, porque una cosa no implica imperativamente la otra. Además, de manera inexplicable hace una interpretación errónea de dicho Reglamento UE, porque afirma y subraya que, según esta normativa europea, "los vehículos $L 1 e-A$ están incluidos en la categoría L1e de ciclomotores", cuando está claro en su Anexo I que solo son ciclomotores los comprendidos en las categorías $L 1 e-B$ y $L 2 e$. Los vehículos de la genérica categoría L1e se denominan "Vehículos de motor de dos ruedas ligeros" y pueden ser L1e-A (ciclos de motor) o L1e-B (ciclomotor de dos ruedas) (art. 4.2.a, y Anexo I del Reglamento UE, tal como expresamente reconoce la Instrucción). Una vez que esta los incluye erróneamente en la categoría de "ciclomotores", concluye que los vehículos L1e-A:

Para autorizar su circulación, deberán estar homologados y matriculados, así como cumplir con el resto de las obligaciones establecidas en el ordenamiento jurídico, relativas al seguro obligatorio, cumplimiento de la frecuencia de inspección técnica, utilización del casco, titularidad del permiso de conducción, etc.

Esto afecta a las bicicletas eléctricas que sobrepasan las especificaciones de una bicicleta de pedaleo asistido, bien por no tener un corte de asistencia del motor a velocidad superior a $25 \mathrm{~km} / \mathrm{h}$, bien por tener una potencia superior a $250 \mathrm{~W}$ (son las llamadas speed bikes).

No hay inconveniente en que la legislación española exija a los vehículos $L 1 e-A$ (ciclos de motor) los mismos requisitos para circular que a los ciclomotores, pero no porque para aquel Reglamento UE tengan la calificación de ciclomotores (Vehículos L1e-B). En todo caso, esta equiparación no la puede hacer una mera Instrucción de la DGT, aunque cabría deducirla del art. 1.1 del Reglamento General de Vehículos, aprobado por Real Decreto 2822/998.

La Instrucción 2019/S-149 TV-108, aclara el equívoco creado por la anterior Instrucción comentada y razona que los vehículos $L 1 e-A$ son ciclos de motor, no ciclomotores, pero que, al exceder de los límites definitorios de un ciclo de pedaleo asistido, deben ser homologados y requieren autorización para circular, seguro obligatorio y autorización para conducir. En cuanto a los VMP la Instrucción se adelanta, con dudosa legalidad, a la reforma del Reglamento General de Vehículos y define en su apartado 4 lo que es un VMP de acuerdo con lo previsto en lo que solo es aún un proyecto de dicha reforma:

Vehículo de una o más ruedas dotado de una única plaza y propulsado exclusivamente por motores eléctricos que pueden proporcionar al vehículo una velocidad máxima por diseño comprendida entre 6 y $25 \mathrm{~km} / \mathrm{h}$. Solo pueden estar equipados con un asiento o sillín si están dotados de sistema de autoequilibrado. Quedan excluidos de esta consideración: vehículos sin sistema de auto-equilibrio y con sillín; vehículos concebidos para competición; vehículos para personas con movilidad reducida; vehículos con una tensión de trabajo superior a 100 VCC o 240 VAC; vehículos incluidos en el ámbito del Reglamento (UE) N2 168/2013. 
En apariencia esta definición es algo más restrictiva que la normativa europea, porque excluye a los vehículos no autoequilibrados que tengan sillín, cualquiera que sea su altura. Sin embargo, en el apartado 6 y a efectos de formular denuncias, la Instrucción tiene en cuenta las medidas de altura del sillín de patinetes eléctricos. A los VMP no se les exige autorización administrativa para circular ni para conducir, ni seguro obligatorio. Si excedieran las características que los definen, los VMP pasarían a ser ciclomotores (vehículos L1e-B y L2e) o motocicletas ( $L 3 e$ ). Nunca sería vehículos $L 1 e-A$, ya que estos, según el Anexo I del Reglamento UE 168/2013, son ciclos diseñados para funcionar a pedal y un patinete no tiene.

Una comparativa de las ordenanzas sobre VMP de Barcelona y Sevilla muestra la disparidad de criterios a la hora de clasificar los VMP, de establecer las vías por las que circular y la edad para conducirlos. Esto indica que, con independencia de la garantía de la autonomía local, es preciso una ordenanza-marco común, elaborada por la Federación de Municipios y Provincias o al menos por la Red de Ciudades por la Bicicleta, para dar seguridad jurídica a los usuarios de los VMP.

\section{Los ciclistas como grupo vulnerable. Seguro, videocámara y Código Penal}

En los anteriores apartados se ha argumentado que las y los ciclistas deben tener un trato normativo preferente porque conducen un vehículo que cumple una función social en la consecución de una movilidad sostenible. En este apartado se razonará la especial protección que se ha de dispensar a los ciclistas por constituir un grupo vulnerable, máxime en un entorno hostil, donde los vehículos a motor ocupan una posición dominante y cuya presencia crea una peligrosidad objetiva.

El Estado social ha procurado remediar esta peligrosidad creando un seguro obligatorio para los vehículos a motor y estableciendo una responsabilidad objetiva de sus conductores por el riesgo creado con motivo de la circulación, debiendo responder de los daños causados a las personas o en los bienes. Además, en el caso de daños a las personas se invierte la carga de la prueba y el conductor solo quedará exonerado de responsabilidad cuando pruebe que los daños fueron debidos a la culpa exclusiva de la persona perjudicada o a fuerza mayor extraña a la conducción o al funcionamiento del vehículo.

Lo ideal sería que no hubiera necesidad de un seguro obligatorio por ausencia de un riesgo objetivo en la conducción, pero dada la hegemonía de los vehículos a motor es un imperativo del Estado social su existencia para proteger a las víctimas. La Ley sobre responsabilidad civil y seguro en la circulación de vehículos a motor, aprobada en su texto refundido por el Real Decreto Legislativo 8/2004, se ocupa de paliar los efectos de la accidentalidad en la conducción viaria y establece entre otras medidas el seguro obligatorio.

En el año 2015 esta Ley fue objeto de una importante y polémica reforma. En apariencia supone un avance, porque mejora la indemnización a las víctimas, pero solo las favorece (a ellas o a sus familias) si han sufrido un traumatismo grave o han fallecido. En cambio, desprotege a la víctima que ha padecido lesiones leves o menos graves, estableciendo la Ley requisitos y condiciones muy ventajosas para las compañías aseguradoras. El resultado parece haber conseguido la cuadratura del círculo. Por un lado, se ha contentado a las más influyentes asociacio- 
nes de víctimas por accidentes de tráfico (que son las que representan a las víctimas más graves), porque la reforma legal ha aumentado el baremo de las indemnizaciones a estas víctimas en caso de accidente, y, por el otro, también se han satisfecho las aspiraciones de las aseguradoras, porque este aumento en la cuantía de las indemnizaciones se compensa con el hecho de que el número de accidentados graves ha disminuido en los últimos años. A esto se une el beneficio que supone mejorar las aseguradoras su posición frente a la mayoría de las víctimas de accidentes de circulación, que son las que sufren lesiones leves o menos graves, que se ven sometidas a requisitos y condiciones más gravosas para que se reconozcan sus lesiones y garantizar su indemnidad. Además, con el argumento de que se había incrementado el baremo retributivo en caso de muerte o de lesiones graves, tras la aprobación de la reforma de la Ley las aseguradoras encarecieron el precio de las pólizas del seguro de vehículos a motor.

A las víctimas ciclistas esta ley les afecta de una manera especial, por el creciente número de víctimas en accidentes contra bicicletas. A ello se une que la obligatoriedad del casco ciclista hace que, en caso de accidente culpable del conductor del vehículo, este pueda ver disminuida su responsabilidad, al poder sentenciarse que ha habido concurrencia de culpas por haber contribuido el ciclista con su omisión del casco al agravamiento de su lesión o a su muerte.

La vulnerabilidad de los ciclistas no se ha combatido de una manera activa. Los poderes públicos no han prestado especial atención al respeto a las normas de seguridad en los adelantamientos, apenas han rebajado los límites de velocidad y han descuidado el estado de los arcenes. En la percepción social y legal el ciclista sigue siendo un estorbo o un obstáculo tanto para los peatones como para los conductores de los vehículos a motor. La normativa de tráfico le confina a circular lo más cerca posible de la orilla derecha de la calzada y se le obliga a protegerse con medidas pasivas y de manera singular con el casco. Cuando hay un accidente lo primero que se destaca es si el ciclista llevaba el casco puesto, aunque el no llevarlo no hubiera mitigado en nada las consecuencias de un atropello del que es solo víctima. Los poderes públicos y los medios de comunicación han fomentado una idea milagrera del casco ciclista sin pararse a pensar que el ciclista no se cae, lo tiran.

En esta situación de desamparo en la que se ven las y los ciclistas ante la impunidad con la que actúan muchos conductores de vehículos a motor poniéndoles en peligro, sobre todo en adelantamientos, ha surgido la iniciativa de grabar los propios ciclistas sus desplazamientos para denunciar en su caso las posibles infracciones sufridas. A la pregunta de si es constitucional esta práctica, la respuesta es que la grabación es lícita si se respetan determinadas condiciones. De manera sucinta puede afirmarse que la grabación efectuada por un ciclista no es diferente de la realizada por cualquier turista en un espacio público. Para compartir y difundir lo grabado, ha de editarse previamente el video, de manera que se borren o difuminen los datos que pudieran servir para identificar a las personas que en él aparecen (caras, matrículas, anagramas de los vehículos, etc.). Sin embargo, si la grabación tiene como destino la denuncia de una infracción ante la autoridad, debe entregarse la original, exenta de cualquier tipo de edición o manipulación. En este caso, al tratarse de una prueba documental y no personal, el denunciado puede tener acceso a la grabación, pero no a los datos del denunciante, que están protegidos constitucionalmente y no exis- 
te un interés legitimo que justifique su entrega, ya que no se vulnera el derecho de defensa del denunciado.

La vulnerabilidad del ciclista se ha visto afectada también por la despenalización en 2015 de las faltas y concretamente las faltas por imprudencia leve en la conducción de vehículos a motor, aunque el resultado de la acción haya sido la muerte de una o varias personas o lesiones graves. El argumento de que el Código Penal (CP) es la última ratio para intervenir en la libertad de las personas ha servido para considerar el legislador que lo relevante es que la víctima sea indemnizada. En estos casos de homicidio o de lesiones por imprudencia leve el cambio de la jurisdicción penal a la civil ha supuesto no solo la desaparición del reproche penal hacia el conductor; también una costosa complicación procesal para las víctimas. De ahí que en ocasiones se haya reclamado el regreso a la vía penal no tanto para criminalizar al autor del accidente como para garantizar una vía reparadora procesalmente más beneficiosa para la víctima.

En 2017, después de muchos accidentes con víctimas que se desplazaban en bicicleta y tras la muerte de un ciclista arrollado por un camión cuyo conductor se dio a la fuga, se organizó una Plataforma por una Ley Justa para modificar el CP en dos sentidos: que una imprudencia al volante con resultado de muerte no pueda ser considerada imprudencia leve y que el abandono de la víctima por el causante del accidente constituya un delito autónomo, con independencia de si la víctima había o no fallecido. La cotidianeidad de los accidentes de tráfico ha banalizado el deber de atención exigible a todo aquel que se pone a los mandos de un vehículo a motor.

Estamos tan acostumbrados a la existencia de accidentes de tráfico, que ha calado la idea de que el ser víctima de un accidente de tráfico es un riesgo de la vida cubierto por un seguro obligatorio que paga por anticipado el propietario del vehículo involucrado en el accidente. Hay conciencia de que hay que reparar el daño causado (seguro obligatorio), pero no de la importancia que tiene el relajamiento leve del conductor, que cada vez más se comporta dentro del coche como si estuviese en la habitación de su casa. Enciende un pitillo, habla por el móvil, atiende al menor que llora, maneja el navegador y la radio... movimientos cotidianos que puede tener nefastos resultados. Al privar de relevancia penal a los despistes en la conducción se envía un mensaje negativo. Se contribuye a que el conductor no sea consciente de las graves consecuencias que puede tener su acción y a que, una vez producido el accidente, su conciencia quede a salvo, protegida por el seguro obligatorio. Dicho en pocas palabras, la despenalización de la imprudencia leve ha contribuido a que el conductor sea más despistado y, por tanto, más imprudente.

La Mesa Española de la Bicicleta se implicó en esa reivindicación Por una Ley Justa proponiendo enmiendas al CP para que retornasen a la categoría de delito las imprudencias leves en la conducción con resultado de muerte o de lesiones graves. El argumento puede resumirse en lo siguiente: tratándose de accidentes de tráfico, el resultado causado no se puede disociar de la calificación del grado de negligencia. La razón está en que conducir un vehículo a motor requiere una autorización o licencia y estar en posesión de la misma obliga a entender que su titular es consciente de la responsabilidad que asume al ponerse a los mandos de un vehículo objetivamente de riesgo. Por tanto, la negligencia de un conductor, aunque sea un despiste (lo que en principio podría considerarse una imprudencia leve) implica la presunción 
de un dolo eventual. El conductor asume que el despiste puede tener consecuencias, aunque sean remotas, porque sabe del riesgo que entraña conducir un vehículo a motor y del atentado que puede causar a valores básicos constitucionalmente tutelados, como la vida o la integridad física de las personas, pero incluso así no desiste de la acción. Si el despiste no tiene consecuencias graves, debe calificarse como imprudencia leve y ser sancionado al margen del CP; no así, aunque se trate de un despiste, si el resultado es relevante. Debe haber un reproche penal hacia esa conducta, aunque solo sea a través de penas de multa. En otras palabras, el despiste de un conductor puede ser considerado en sí una negligencia leve, pero su imprudencia ha de ser siempre calificable de grave o menos grave cuando causa la muerte o lesiones tipificadas como delito en el CP.

Por otra parte, la reforma intentaba corregir un defecto grave en el CP y es que se sancionaba en concurso ideal de delitos el abandono de la víctima por el culpable del accidente, es decir, no se consideraba un delito autónomo y, además, solo se sancionaba si la víctima quedaba malherida, no si había fallecido. Frente a los que consideraban que con la reforma se pretendía proteger dos veces el mismo bien jurídico, la vida o la salud de la persona accidentada primero y abandonada después, tuve oportunidad de argumentar en una comparecencia ante el Congreso de los Diputados que con los delitos de homicidio o de lesiones por imprudencia al volante lo que se protege es la integridad física de la víctima. Con el delito de omisión de socorro tras causar el accidente lo que se ampara es su integridad moral, ya que la persona es abandonada como si fuese un animal o un obstáculo, degradando su dignidad a la de un mero objeto en la calzada. Por eso es un error conceptual (que aún existe hoy en el CP tras la reforma) diferenciar la sanción penal según el estado en el que haya quedado la víctima abandonada (muerta o con lesiones). Es más, si se quisiera hacer una escala de penas en función del daño causado por el hecho de huir abandonando a la víctima, habría que prever más pena para el resultado de víctimas con lesiones, que quedan desamparadas y con riesgo de morir, que las víctimas mortales, por las que ya nada se puede hacer.

Finalmente se reformó el CP con algunos cambios más beneficiosos que se aceptaron a través de enmiendas. Las mejoras pueden resumirse en las siguientes: determinados supuestos de imprudencia al volante con resultado de muerte o de lesiones serán considerados siempre imprudencias graves; muchos homicidios o lesiones causados por imprudencia al volante no serán derivados a la vía civil y recibirán una sanción penal, al tener que ser calificados, al menos, como imprudencia menos grave; a partir de ahora, se considerará siempre imprudencia menos grave si el accidente mortal o lesivo causado por el conductor de un vehículo a motor o ciclomotor fue consecuencia de una infracción grave de las normas de tráfico; habrá un mayor castigo penal si el accidente causante de homicidio y/o lesiones por imprudencia grave al volante fue especialmente trágico, provocando más de una muerte o una muerte y un lesionado grave; las lesiones relevantes para el delito de imprudencia grave o menos grave al volante no solo serán las más traumáticas (pérdida de un miembro o deformidades) sino también las que requieran objetivamente para su sanidad, además de una primera asistencia facultativa, tratamiento médico o quirúrgico; por último, se tipifica como delito autónomo el simple hecho de abandonar voluntariamente y sin riesgo propio o 
de terceros el lugar de los hechos tras causar un accidente con el vehículo a motor o ciclomotor, dejando una o varias personas muertas o con lesiones; además, se establece un incremento de la pena si el accidente fue causado por imprudencia del conductor, sea esta grave, menos grave o leve.

En suma, el CP, aunque sea la última ratio para intervenir en la vida o libertad de las personas, es un instrumento importante del Estado social de derecho para garantizar una movilidad segura, sobre todo cuando se trata de proteger a víctimas que pertenecen a grupos no solo especialmente vulnerables (peatones, ciclistas), sino también fundamentales para la consecución de una movilidad sostenible. 


\section{Referencias bibliográficas}

\section{Sobre REgUlación JURÍDicA DE LA BICICLETA}

Existen numerosas publicaciones sobre movilidad sostenible y sobre bicicleta y movilidad, pero no que tengan por objeto un análisis jurídico de la materia. El único libro que trata el tema con carácter general es:

Boix, Andrés y Marzal, Reyes (eds.) (2014). Ciudady movilidad. La regulación de la movilidad urbana sostenible. Valencia: Universidad de Valencia.

Bastida, Francisco J. (2014). La movilidad ciclista en España y su regulación jurídica. En Boix, Andrés y Marzal, Reyes (eds.) (2014). Ciudad y movilidad. La regulación de la movilidad urbana sostenible (pp. 153174). Valencia: Universidad de Valencia.

Sobe propuestas de un Plan Estratégico Estatal DE LA BICICLETA

Mesa Nacional de la Bicicleta (2014). Directrices para un Plan Estratégico Estatal de la Bicicleta. Recuperado el 04 de abril de 2020 de: https:/ / conbici.org/planestrategico-estatal-de-la-bicicleta/plan-estrategicoestatal-de-la-bicicleta-completo.

Estrategia Estatal por la Bicicleta: https:/ / conbici.org/ plan-estrategico-estatal-de-la-bicicleta/plan-estrategico-estatal-de-la-bicicleta-completo.

Sobre El Proyecto de Reforma del Código GeneRAL DE CirCulaCión

Consejo del Estado Español (2014). Dictamen 885/2014 del Consejo de Estado sobre el proyecto de reforma del Reglamento General de Circulación. Recuperado el 04 de abril de 2020 de https:/ / www.boe.es/buscar/doc. php?id=CE-D-2014-885.

Bastida, Francisco J. (2015). La bicicleta en el tejado. La reforma del Reglamento General de Circulación y el dictamen del Consejo de Estado. Informe sobre el Dictamen 885/2014. Recuperado el 04 de abril de 2020 de: https:/ / ciclojuristascom.files.wordpress. com/2015/03/informe-sobre-el-dictamen-de-consejo-de-estado-reglamento-circulacic3b3n.pdf.
Mesa española de la bicicleta (2018a). Informe presentado por la Mesa Española de la Bicicleta de la Bicicleta sobre el proyecto de 2013 de reforma del Reglamento General de Circulación de 2003 y sobre el proyecto de Ley de 2014 de reforma de la Ley de Tráfico, Circulación de vehículos a motor y Seguridad Vial de 1990. Recuperado el 04 de abril de 2020 de: https:/ / ciclojuristascom.files. wordpress.com/2018/10/enmiendas-a-reformasnormativas-propuestas-por-la-dgt.pdf.

Sobre Regulación de la circulación de Vehículos de Movilidad Personal

Instrucción de la DGT de 2016, 16/V-124: http:/ / www.dgt.es/Galerias/seguridad-vial/normativalegislacion/otras-normas/modificaciones/2016/ Instr_16_V_124_Vehiculos_Movilidad_Personal.pdf.

Instrucción de la DGT de 2019, 9/V-134: http:/ / www. dgt.es/Galerias/seguridad-vial/normativa-legislacion/otras-normas/modificaciones/19.V-134-Matriculacion-de-vehiculos-L1e-A.pdf.

Instrucción de la DGT de 2019, S-149 TV-108: http:/ / www.dgt.es/Galerias / seguridad-vial/normativalegislacion/otras-normas/normas-basicas/Intruccion-VMP-y-otros-vehiculos-ligeros.pdf.

Normativa del Ayuntamiento de Barcelona sobre los VMP: https://www.barcelona.cat/mobilitat/es/medios-de-transporte/vehiculos-movilidad-personal

Ordenanza de movilidad de Sevilla y VMP: https:/ / www.sevilla.org/servicios/movilidad/modificacionde-la-ordenanza-de-circulacion-de-la-ciudad-de-sevilla.

Sobre Estado Social, DERECHOS FUNDAMENTALES Y PROTECCIÓN DE LOS CICLISTAS

Web de la red Ciclojuristas: https:/ / ciclojuristascom. wordpress.com.

Mesa española de la bicicleta (2018b). Enmiendas de la Mesa Española de la Bicicleta a la reforma del Código Penal. Ciclojuristas. Recuperado el 04 de abril de 2020 de: https:/ / ciclojuristascom.wordpress.com/?s=codigo+penal. 
Bastida Freijedo, Francisco J. (2020). La Bicicleta y el Estado social de derecho. Hábitat y Sociedad, 13, 63-85.

<http://dx.doi.org/10.12795/HabitatySociedad.2020.i13.05>

$\bigcirc$ 


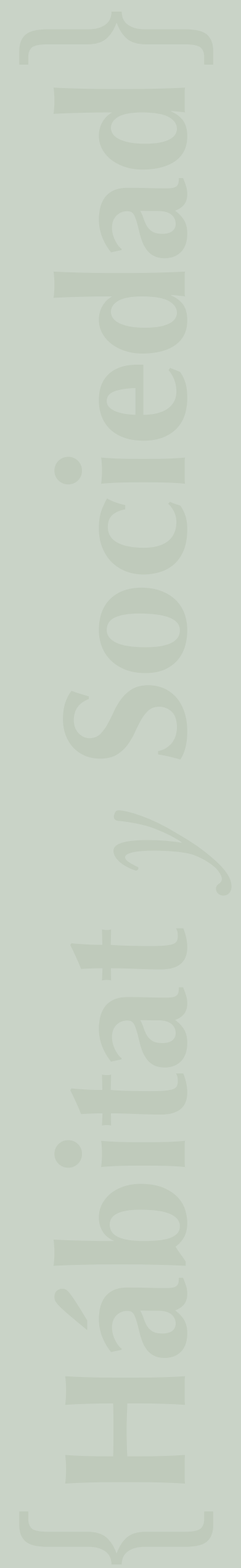

